\title{
Stress simulation analysis of composite double-layer flywheel energy storage rotor
}

\author{
Zhang Xinglei ${ }^{\mathrm{a}}$, Wang Mei ${ }^{\mathrm{b}}$ \\ Department of Mechanical and Electrical Engineering, Zaozhuang University, \\ Zaozhuang 277160, China; \\ azhangxingfulove@163.com, bwangmei25@sina.com
}

Keywords: composite material, double layer flywheel rotor,flywheel energy storage density, stress analysis

Abstract.Flywheel energy storage rotor generates strong centrifugal inertia force at high speed rotating state, and the centrifugal force causes the internal composite flywheel rotor stress. If the stress exceeds the ultimate strength of composite flywheel rotor, it will be destroyed.Using the double ring flywheel rotor design, it can offset a portion for high-speed rotation of the centrifugal stress because of the interference fit between the layers appear at the beginning of prestress, it also can be understood as the increased speed and flywheel storage flywheel energy storage system in a certain extent. Through the ANSYS stress analysis, the results showed that the radial stress produced by the double ring flywheel rotor is reduced by $11.706 \mathrm{Mpa}$ compared with the radial force produced by the single layer flywheel rotor, and radial stress is the key factor to restrict the promotion, so using the double ring flywheel rotor can improve flywheel speed and increase the flywheel energy storage.

\section{Introduction}

Flywheel energy storage system is actually a device for storing kinetic energy. Its structure mainly includes high-speed rotating flywheel rotor, integrated electric / generator, magnetic bearing support system, power electronic converter, vacuum chamber and so on. Compared with traditional energy storage methods, flywheel energy storage system has the advantages of high energy storage density, high efficiency, high power, no pollution, long life and so on. ${ }^{[1-3]}$

Flywheel energy storage rotor generates strong centrifugal inertia force at high speed rotating state, and the centrifugal force causes the internal composite flywheel rotor stress. If the stress exceeds the ultimate strength of composite flywheel rotor, it will be destroyed.The radial stress of a single layer flywheel rotor is much smaller than the circumferential stress at high speed.However, The radial allowable stress of the ring flywheel rotor with high strength composite ring wound $\sigma_{r} \mid$ is far smaller than the allowable stress of its circumferential direction $\left\lfloor\sigma_{\theta}\right\rfloor$, so when the single ring flywheel rotor with circumferential winding is in high speed rotating state, it is very likely that the rotor's failure or damage is caused by the lack of radial strength. By reasonably changing the radial thickness or axial thickness of the ring flywheel, the radial stress can be reduced correspondingly ${ }^{[4]}$, but the extent of the reduction does not necessarily satisfy the radial strength limit of the rotor. One of the effective ways to reduce the radial stress is to use a certain amount of interference to assemble each layer of rings into a double ring. There is an interaction between the two rings due to a certain amount of interference, and the reaction force is opposite to the radial stress produced by the high speed rotation, so a part of radial stress is counteracted.It effectively solves the defects of insufficient flywheel rotor radial strength, then gets a high rim velocity and improves the flywheel energy storage. 


\section{Stress distribution of double layer composite flywheel rotor}

The stress distribution between the rings of the double layer ring flywheel rotor can be obtained by the equilibrium equation of the radial displacement. The expression of the equation in cylindrical coordinates is ${ }^{[5]}$ :

$$
\frac{\partial \sigma_{r}}{\partial_{r}}+\frac{\sigma_{r}-\sigma_{\theta}}{r}+\rho \omega^{2} r=0
$$

In the formula $\sigma_{r} \longrightarrow$ Radial stress

$$
\begin{aligned}
& \sigma_{\theta}-\text { Hoop stress } \\
& \rho-\text { Material density } \\
& \omega-\text { Flywheel rotation angular velocity }
\end{aligned}
$$

Taking the two layer composite flywheel rotor as the research object, the stress and radial displacement formula of the ring of orthotropic material subjected to internal pressure $(P)$ and external pressure $(Q)$ is obtained by Tutuncu ${ }^{[6]}$ :

$$
\begin{aligned}
& \sigma_{\theta}=\frac{P \lambda^{k+1}-Q}{1-\lambda^{2 k}} \lambda\left(r / r_{o}\right) k-1+\frac{P-Q \lambda^{k-1}}{1-\lambda^{2 k}} k \lambda^{k+1}\left(r_{r} r_{o}\right)-k-1 \\
& \sigma_{r}=\frac{P \lambda^{k+1}-Q}{1-\lambda^{2 k}}\left(r / r_{o}\right) k-1+\frac{P-Q \lambda^{k-1}}{1-\lambda^{2 k}} \lambda^{k+1}\left(r_{/} r_{o}\right)-k-1 \\
& \mu_{r}=\frac{r_{O}}{E_{\theta}\left(1-\lambda^{2 k}\right)}\left[\left(P \lambda^{k+1}-Q\right)\left(k-v_{\theta r}\right)\left(r / r_{o}\right) k+\left(P-Q \lambda^{k-1}\right)\left(\lambda-u_{\theta r}\right) \lambda^{k+1}\left(r_{r} r_{o}\right)-k\right]
\end{aligned}
$$

The internal pressure $P=\frac{\bar{\sigma} \theta^{(k+1)} \cdot t}{R_{i}^{(k+1)}}, \bar{\sigma} \theta^{(k+1)}$ is the average circumferential stress of the current winding layer, $t$ is the layer thickness of the composite material, $R_{i}(k+1)$ is the inner radius of the $k+1$ layer ring.

\section{Stress simulation analysis of double layer composite flywheel rotor}

In this paper, the two layer flywheel rotor is chosen as the analysis object, and the equal thickness design is adopted according to the actual working space of the flywheel,Outer diameter $R_{0}=0.455 \mathrm{~m}$, internal diameter $r_{0}=0.414 \mathrm{~m}$ The outer diameter $R_{1}=0.414 \mathrm{~m}$, inner diameter $r_{1}=0.373 m$, height $h=1.16 m$ and interference amount $\varepsilon=0.2 m m$. The outer layer is 
made of carbon fiber T700/E-765Epoxy and the inner layer is made of glass fiber / epoxy resin, and the performance parameters are shown in Table 1:

Table 1 composite parameter ${ }^{[7}$

\begin{tabular}{ccccccc}
\hline Material name & $\begin{array}{c}\text { Density } \\
{\left[\mathrm{kg} / \mathrm{m}^{3}\right]}\end{array}$ & $\begin{array}{c}\text { Elastic } \\
\text { modulus } \\
{[\mathrm{GPa}]}\end{array}$ & $\begin{array}{c}\text { Shear } \\
\text { modulus } \\
{[\mathrm{GPa}]}\end{array}$ & $\begin{array}{c}\text { poisson's } \\
\text { ratio }\end{array}$ & $\begin{array}{c}\text { Circumferenti } \\
\text { altensile } \\
\text { strength[MPa] }\end{array}$ & $\begin{array}{c}\text { Radial } \\
\text { tensile } \\
\text { strength } \\
{[\mathrm{MPa}]}\end{array}$ \\
\hline $\begin{array}{c}\text { T700/E-765Epoxy } \\
\text { Glass fiber / } \\
\text { epoxy resin }\end{array}$ & 1650 & 129 & 10 & 0.25 & 2550 & 88.9 \\
\hline
\end{tabular}

The three-dimensional model of the double-layer composite flywheel rotor is shown in Fig.1:

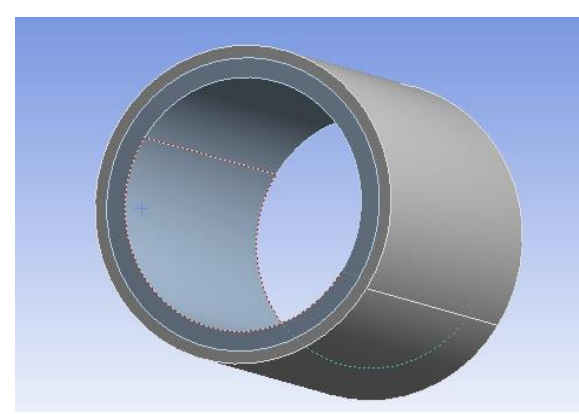

Fig.1 double layer composite flywheel rotor model

The double-layer composite material flywheel model is imported into ANSYS and divided into grids, as shown in Fig.2:

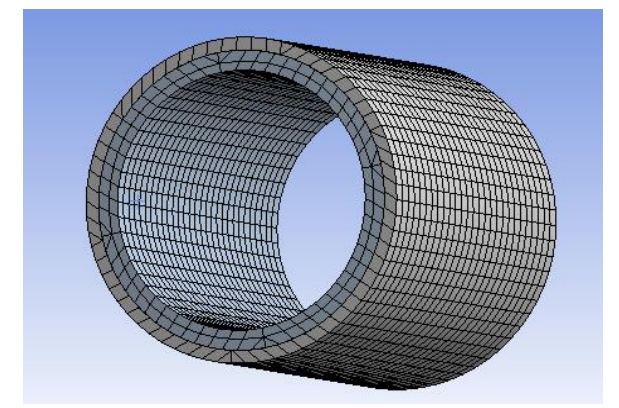

Fig. 2 mesh diagram of flywheel rotor

This paper uses sweep division method slightly grid and obtains a total of 8628 nodes, 5146 units. The grid is arranged in rows and arranged in a regular shape, which is conducive to the load control and convergence, and the grid is a hexahedral element, so it can make the results more accurate.

The coordinate system is converted into a cylindrical coordinate system by solving ANSYS, and the stress analysis results of the flywheel speed 16000rmp are obtained, such as Table 2, Fig.3, Fig.4: 
Table 2 stress analysis results of single layer and double layer flywheel rotor

\begin{tabular}{cccc}
\hline number of plies & $\begin{array}{c}\text { Radial } \\
(\mathrm{Mpa})\end{array}$ & stress & $\begin{array}{c}\text { Hoop stress } \\
(\mathrm{Mpa})\end{array}$ \\
\hline Mono-layer & 43.415 & 912.8 \\
Double-deck & 31.706 & 1071.4 \\
\hline
\end{tabular}

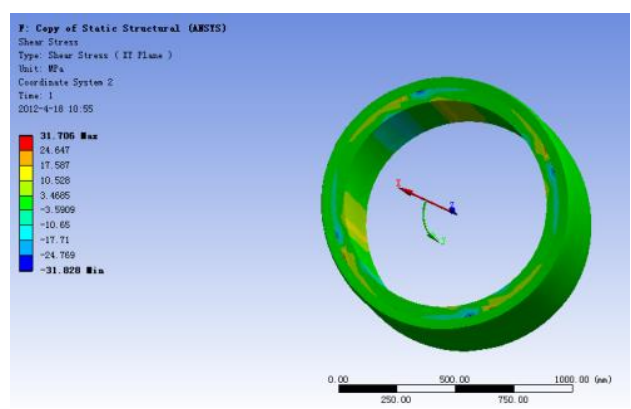

Fig.3 double layer radial stress diagram

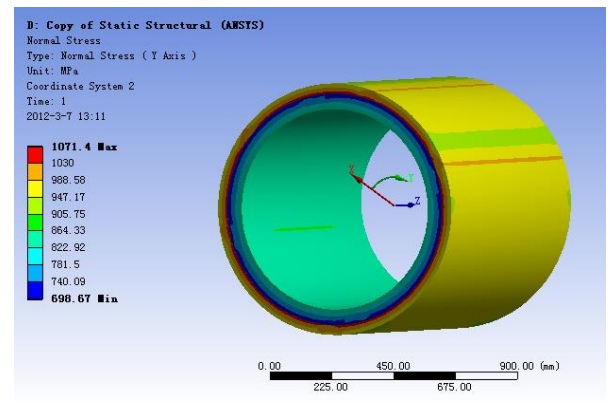

Fig.4 double layer hoop stress diagram

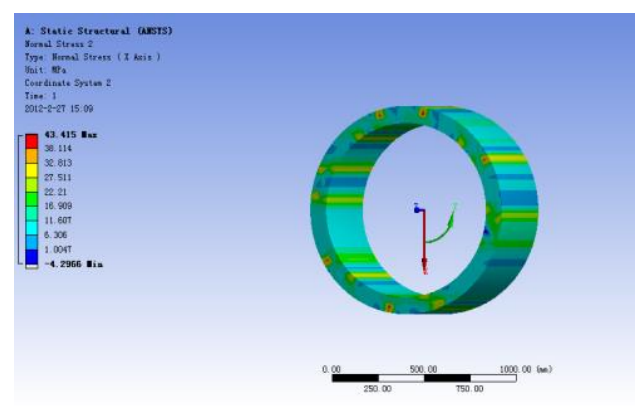

Fig.5 radial stress diagram of single layer flywheel rotor

The radial stress and circumferential stress distribution of the double layer composite flywheel rotor under high speed rotation are given. The stress distribution of the single layer and equal thickness ring flywheel rotor is also shown in Fig.5. The radial stress produced by the double ring flywheel rotor is reduced by $11.706 \mathrm{Mpa}$ compared with the radial force produced by the single layer flywheel rotor,thus it overcomes the limitation of the radial strength of the composite material to a certain extent..

\section{Conclusions}

Using the double ring flywheel rotor design, it can offset a portion for high-speed rotation of the centrifugal stress because of the interference fit between the layers appear at the beginning of prestress, it also can be understood as the increased speed and flywheel storage flywheel energy storage system in a certain extent. Through the ANSYS stress analysis, the results showed that the radial stress produced by the double ring flywheel rotor is reduced by $11.706 \mathrm{Mpa}$ compared with 
the radial force produced by the single layer flywheel rotor, and radial stress is the key factor to restrict the promotion, so using the double ring flywheel rotor can improve flywheel speed and increase the flywheel energy storage.

\section{References}

[1] Mechanical engineering manual, editing Manual of electrical engineering manual, Mechanical Engineering Handbook,volume fifth,mechanical design (two). Beijing: Mechanical Industry Press, 1982.12.

[2] Series of electrical new and high technology (third volume), Beijing: Mechanical Industry Press, 2000.4

[3] Jiang Shuyun, Wei Chinese,Shen Zupei.The current situation of the development of technology of flywheel energy storage. Journal of solar energy, 2000,21 (4): 427 433

[4] Kirk J A, Schmidt J R, Sullivan G E,et al. An open core rotator design methodology. In: proceedings of IEEE National Aerospace and Electronics Conference, Piscataway, NJ,USA, 1997:594 601

[5] Ha S K, Yang H I,Kim D J,Optimal design of a hybrid composite flywheel with a permanent magnet rotor. Journal of Composite Materials. 1999,33(16):1544 1575

[6] N.Tutuncu. Effect of anisotropy on stresses in rotating discs[J], International of Mechanical Science.1995,37:873 881

[7] http://www.matweb.com 